\title{
Oral behaviors, bruxism, malocclusion and painful temporomandibular joint clicking: is there an association?
}

\section{Rodrigo Lorenzi POLUHA ${ }^{\text {(a) }}$ Giancarlo De la Torre CANALES(a) Leonardo Rigoldi BONJARDIM(b) Paulo César Rodrigues CONTI(a)}

(a) Universidade de São Paulo - USP, Bauru School of Dentistry, Department of Prosthodontics, Bauru, SP, Brazil.

(b) Universidade de São Paulo - USP, Bauru School of Dentistry, Department of Biological Sciences, Bauru, SP, Brazil.

Declaration of Interests: The authors certify that they have no commercial or associative interest that represents a conflict of interest in connection with the manuscript.

Corresponding Author:

Rodrigo Lorenzi Poluha

E-mail:rodrigopoluha@gmail.com

https://doi.org/10.1590/1807-3107bor-2021.vol35.0090

Submitted: July 23, 2020

Accepted for publication: December 15, 2020

Last revision: February 16, 2021
Abstract: The present cross-sectional case-control study aimed to determine if there is an association between specific oral behaviors, sleep bruxism (SB), awake bruxism (AB), and painful temporomandibular joint (TMJ) clicking. Ninety individuals were dived into three groups; Group $1(\mathrm{n}=30)$ : painful TMJ clicking; Group $2(\mathrm{n}=30)$ : painless TMJ clicking; and Group $3(\mathrm{n}=30)$ : control group. The following clinical data were studied: oral behaviors (unilateral chewing, gum chewing, nail biting, foreign objects biting, leaning with jaw against the hand, and sleeping in a position that pressures the jaw), SB, AB (including the frequency in 10 days, evaluated by ecological momentary assessment), and malocclusions investigated based on clinical inspections (anterior open bite, posterior cross-bite, abnormal overbite/overjet, occlusal guidance, mediotrusive and/or laterotrusive interferences, retruded contact position to maximum intercuspation slide, missing posterior teeth). All statistical tests (Kolmogorov-Smirnov, chi-square, and one-way ANOVA) were performed with a 5\% significance level. Group 1 had the highest frequency of and a significant association with leaning with jaw in the hand, sleeping position that pressures the jaw, gum chewing, nail biting, and $\mathrm{AB}(\mathrm{p}<0.05)$. Gum chewing, nail biting, and $\mathrm{AB}$ were associated with Group 2 only when compared to Group 3 ( $\mathrm{p}<0.05)$. No significant difference among groups was found for other behaviors (unilateral chewing and foreign objects biting), SB, and all malocclusions ( $p>0.05)$. It can be concluded that patients with painful TMJ clicking had a higher frequency of and a significant association with some specific harmful behaviors and $\mathrm{AB}$.

Keywords: Temporomandibular Joint; Temporomandibular Joint Disc; Pain.

\section{Introduction}

Temporomandibular disorders (TMDs) are a group of disorders involving the masticatory muscles, the temporomandibular joint (TMJ), and the associated structures. ${ }^{1}$ The main TMJ-related disorders are internal derangements and inflammatory disorders. ${ }^{2}$ Disc displacement with reduction (DDWR) is the most common internal derangement and accounts for about $41 \%$ of TMD clinical diagnoses. ${ }^{3}$ In this condition, when the mouth is closed, the articular disc is displaced in relation to the condyle and when the mouth is open the disc returns to its original 
position in the intermediate area between the condyle and the articular tubercle ${ }^{2,3}$. Clinically, DDWR is related to TMJ clicking, which occurs when the disc is displaced and repositioned during mandibular movements. ${ }^{3,4}$ TMJ clicking corresponds to $30.7 \%$ of the clinical signs of TMD and is one of the most common complaints of patients. ${ }^{5}$

Although TMJ clicking is usually painless, in some patients, pain can be a comorbid symptom, characterizing a more serious condition such as painful TMJ clicking, in which pain located in the TMJ area and surrounding tissues occurs or is intensified when clicking, possibly due to a compression of the bilaminar zone and TMJ inflammation. ${ }^{2,3,6,7}$ Arthralgia is the inflammation of the joint capsule and/or of the TMJ synovial lining, generating pain and sensitivity ${ }^{2}$. Alone, arthralgia corresponds to $26.5 \%$ of TMD diagnosis, ${ }^{8}$ and the presence of TMJ clicking increases the relative risk of developing arthralgia. ${ }^{9}$

The etiology of TMJ clicking and arthralgia are directly or indirectly partly related to biomechanical forces applied to the TMJ, exceeding the adaptive capacity of the individual. ${ }^{2,10}$ These excessive biomechanical forces can increase disc compression, squeezing the disc off the condyle, increasing the sensitivity of retrodiscal tissues, and promoting the production of inflammatory mediators. ${ }^{29,10}$ TMJ clicking and arthralgia have been separately investigated in association to oral behaviors, bruxism, and malocclusion (usually when there is excessive biomechanical forces) in an attempt to establish a causal relationship and possible treatment strategies., ${ }^{5,11,12,13}$ However, no study addressed these factors in patients with painful TMJ clicking (DDWR plus arthralgia in the same TMJ). This information may help to improve the understanding of this condition and to formulate a better clinical approach.

Therefore, the present study aimed to determine if there is an association between oral behaviors, bruxism, malocclusion, and painful TMJ clicking. The null hypothesis is that the variables studied would not present any difference.

\section{Methodology}

This research was approved by the Research Ethics Committee of the Bauru School of Dentistry,
University of São Paulo, Bauru, São Paulo, Brazil (CAAE: 88592018.0.0000.5417/ N: 2.725.838) and was registered at the Brazilian Registry of Clinical Trials (REBEC: RBR-4j5g96). All individuals were informed about the research purposes and signed a free informed consent form. This cross-sectional case-control study was conducted following the Helsinki Declaration and the recommendations of the Strengthening the Reporting of Observational Studies in Epidemiology (Strobe) guidelines. ${ }^{14}$

The sample size calculation was performed using G*Power 3.1.9.2 software (Düsseldorf, Germany). The following parameters were considered: a) test power of 0.8 ; b) 0.016 significance level, considering the multiple comparisons of three families of variables (oral behaviors, bruxism, and malocclusion) and according to Bonferroni's correction in which the standard alpha error of 0.05 is divided by the number of families of comparisons, ${ }^{15}$ and, c) effect size of 0.4 for the analysis of variance (ANOVA) with one inter-subject factor, i.e., groups $(n=3)$. Thus, the total sample size was 90 individuals equally divided into three groups: group 1 was composed of 30 patients (22 females, 8 males, mean age of $33.4 \pm 13.53$ years) with unilateral painful TMJ clicking (DDWR plus arthralgia in the same TMJ); group 2 was composed of 30 patients ( 22 females, 8 males, mean age of $32.8 \pm 13.56$ years) with unilateral painless TMJ clicking (only DDWR); and group 3 (control group) was composed of 30 asymptomatic individuals (22 females, 8 males, mean age of $31.36 \pm 10.64$ years) with no TMJ clicking and no arthralgia. The individual was considered the unit of observation. The study design and sample formation were based on a previous investigation on the anatomy of the TMJ to understand the concomitance presence of arthralgia and DDWR.?

The sample was obtained from 231 Brazilian individuals, over 18 years old, that consecutively sought regular dental treatment (control group) or presented with complaint of clicking and/or pain in TMJ area at the Bauru School of Dentistry, Orofacial Pain Clinics, from September 2018 to July 2019. A single examiner (R.L.P.), TMD and Orofacial Pain specialist and professor, conducted all clinical examinations. The patients were then allocated to one of the groups according to the clinical examination, 
based on the official Portuguese version of the Research Diagnostic Criteria for Temporomandibular Disorders (RDC/TMD) - Axis I.

One hundred and forty one individuals were excluded due to pain other than arthralgia, such as myofascial pain (60 individuals), TMJ sound other than clicking (crepitation or terminal thud) (35 individuals), having had previous surgical intervention in the TMJ (5 individuals), having systemic conditions such as fibromyalgia (6 individuals), osteoarthritis (4 individuals) and autoimmune arthritis like rheumatoid arthritis (3 individuals) or any degenerative joint disease ( 3 individuals), wearing removable dental prostheses (5 individuals), ongoing orthodontic treatment (9 individuals), or in continuous use of medications such as analgesics and anti-inflammatory drugs (11 individuals). The following clinical data were studied: oral behaviors (OBs), sleep bruxism (SB), awake bruxism (AB), and malocclusion.

\section{Oral behaviors}

OBs previously reported in the literature as related to TMJ pain and/or TMJ noise ${ }^{5,11}$ were evaluated (based on the previous month) by using part of the Oral Behaviors Checklist ${ }^{16}$ self-reported questionnaire. Five OBs were studied during wakefulness: unilateral chewing, gum chewing, nail biting, foreign objects biting (e.g. pen), and leaning with jaw in the hand, such as cupping or resting the chin in the hand. There were 5 possible answers for the frequency of these OBs: none of the time, a little of the time, some of the time, most of the time, and all of the time.

One OB was studied during sleep. It was investigated the habit of sleeping in a position that puts pressure on the jaw (for example, on stomach, on the side of TMJ complaint) and how often. There were 5 possible answers for the frequency of this OB: none of the time, < 1 night/month, 1 to 3 nights/month, 1 to 3 nights/week, and 4 to 7 nights/week.

For analyses, OBs were evaluated dichotomously: present or absent. The OB was considered as "present" when the frequency was "most of the time" or "all of the time" or "1 to 3 nights/week" (for OBs studied during wakefulness) or " 4 to 7 nights/week (for the OB studied during sleep). ${ }^{5,11,16}$

\section{Sleep bruxism}

Considering the diagnostic grading system, the presence of "Probable SB" was based on a positive self-report with a positive clinical inspection. ${ }^{17}$ To be considered as having "Probable SB" the individual should answer "yes" to the question "Have you been told or do you notice that you grind your teeth or clench your jaw while sleeping?" (with the frequency of at least 1-3 nights/week among the options: none of the time, $<1$ night/month, 1 to 3 nights/month, 1 to 3 nights/week, and 4 to 7 nights/week), and in the clinical inspection, abnormal tooth wear should be visible within the enamel or dentin exposure and loss of clinical crown height of $<1 / 3$ ). In this study, the examination consisted of the inspection of the last molar in the right mandibular arch ${ }^{18}$.

\section{Awake bruxism}

Considering the diagnostic grading system, the

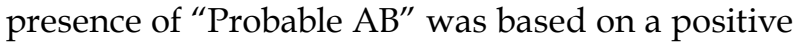
self-report with a positive clinical inspection. ${ }^{17}$ To be considered positive to the presence of "Probable AB" the individual should answer "yes" to the question "During the day, do you do repetitive or sustained tooth contact and/or bracing or thrusting of the mandible?", with the frequency of at least "most of the time" among the options: none of the time, a little of the time, some of the time, most of the time, and all of the time; the same parameter described for $\mathrm{SB}$ was used in the clinical inspection. ${ }^{18}$

The frequency of $A B$ was studied by an instrumental assessment (ecological momentary assessment [EMA]), using a free application for smartphone called No Clenching ${ }^{\circledR}$ (Live iDeas, Palhoça, Brazil) in the Portuguese version (Desencoste seus dentes $\left.{ }^{\circledR}\right)$. This system sends alerts during the day to collect data on self-reported AB. The software was programmed to send 12 alerts/day, every hour, from 9.00 AM to 9.00 PM. The individuals were instructed to answer "yes" or "no" on real time at every alert for any $\mathrm{AB}$ activity (teeth contact, teeth clenching, teeth grinding, bracing). All the possible conditions were previously explained to the participants. Participants were also taught to disregard the alert if it happened while performing functional activities, such as eating or talking. Data were recorded over ten days, 
gathering 120 answers, but only the first 100 answers were considered for statistical analysis (individuals with less than 100 answers were excluded). After the observation period, the software generated a report, which was sent to the researcher via email by the participants. To evaluate the frequency of $\mathrm{AB}$, all individuals were asked to use the EMA, even those who self-reported not having $\mathrm{AB}$ in the anamnesis.

\section{Malocclusion}

The following malocclusion conditions were investigated, based on clinical inspection protocols adopted in previous studies. ${ }^{13,19}$ anterior open bite (present/absent), posterior cross-bite (present/absent), overbite (normal/ $\geq 4 \mathrm{~mm}$ ), overjet (normal/ $\geq 5 \mathrm{~mm}$ ), canine guidance (present/absent), mediotrusive and/or laterotrusive interferences (present/absent), retruded contact position to maximum intercuspation (RCP-MI) slide (normal/ $\geq 2 \mathrm{~mm}$ ), and $\geq 5$ missing posterior teeth (present/absent).

\section{Statistical analysis}

All data were tabulated, submitted to descriptive analysis, and assessed for normal distribution with the Kolmogorov-Smirnov test. A chi-square test was used to compare the presence of categorical variables (OBs, SB, AB, and occlusal features) among groups. One-way analysis of variance (ANOVA) followed by post hoc Tukey's test was used to compare the frequency of $\mathrm{AB}$. A 5\% significance level was used for all tests. Data were analyzed using SPSS Statistics 25.0 software (IBM®, New York, USA).

\section{Results}

The descriptive data (frequency distribution) for OBs, $\mathrm{SB}, \mathrm{AB}$, and malocclusion are shown in Table 1. In the comparison among all groups, patients with painful TMJ clicking had a higher frequency and a significant association with the OBs of leaning with hand on the jaw, sleeping in a position that puts pressure on the jaw, gum chewing; nail biting, and AB ( $p$ < 0.05). Patients with painless TMJ clicking had a significant association with gum chewing, nail biting, and $\mathrm{AB}$, only when compared to the control group $(p<0.05)$. The other OBs (unilateral chewing and foreign objects biting), BS, and all malocclusion features showed no significant difference $(p>0.05)$ among groups (Table 1).

Regarding the frequency of $\mathrm{AB}$, evaluated by EMA, all individuals of the sample answered the app at least 100 times, and therefore, no one was excluded from this analysis. Group 1 (painful TMJ clicking) had a higher mean number of "Yes" answers of AB activity, $37.43 \pm 33.75$ (range 0-91), followed by group 2 (painless TMJ clicking), $22.40 \pm 24.59$ (range 0-88), and group 3 (control group), $5.17 \pm 6.05$ (range $0-23$ ). Considering the total sample $(\mathrm{n}=90)$, there were $21.67 \%$ of positive responses on real time report of $A B$ activity. Significant differences $(p<0.05)$ in frequency of "Yes" answers for AB activity among groups were found (Table 2).

\section{Discussion}

The present study found that leaning with hand on the jaw, sleeping in a position that puts pressure on the jaw, gum chewing, nail, and $A B$ have a significant association with patients with painful TMJ clicking when compared to patients with painless TMJ clicking and to the control group. SB and malocclusion were not related to this condition. Thus, the null hypothesis was partially rejected.

Only specific OBs previously reported in the literature as related to TMJ pain and/or TMJ noise were evaluated. In the present study, four OBs showed a statistically significant difference among groups. The behaviors of lean with your hand on the jaw and sleeping position that pressures the jaw were reported, respectively, by $37.8 \%$ and $42.2 \%$ of the individuals (considering the total sample); also, both were significantly associated only with painful TMJ clicking (Table 1). Similar findings were reported previously, when the same OBs were positively related to TMJ pain and TMJ clicking, individually, ${ }_{11}^{11}$ although higher frequencies were found. The association between these OBs and painful TMJ clicking supports the hypothesis that activities that compress the TMJ could be a contributing factor to the internal derangement of the joint by increasing the intra-articular pressure..$^{20}$ Also, high TMJ intra-articular pressure can result 
Table 1. Descriptive data for oral behaviors, bruxism, and malocclusion plus p-value of chi-square test (frequency).

\begin{tabular}{|c|c|c|c|c|c|}
\hline \multirow{2}{*}{ Variables } & Painful TMJ clicking & Painless TMJ clicking & Control group & Total & \multirow{2}{*}{$\mathrm{p}$-value } \\
\hline & $(n=30)$ & $(n=30)$ & $(n=30)$ & $(n=90)$ & \\
\hline \multicolumn{6}{|c|}{ Leaning with hand on the jaw } \\
\hline Present & $18(60.0 \%)^{A}$ & $10(33.3 \%)^{\mathrm{B}}$ & $6(20.0 \%)^{B}$ & $34(37.8 \%)$ & \multirow{2}{*}{$0.005^{*}$} \\
\hline Absent & $12(40.0 \%)^{A}$ & $20(66.7 \%)^{B}$ & $24(80.0 \%)^{\mathrm{B}}$ & $56(62.2 \%)$ & \\
\hline \multicolumn{6}{|c|}{ Sleeping in a position that pressures on the jaw } \\
\hline Present & $20(66.7 \%)^{A}$ & $11(36.7 \%)^{\mathrm{B}}$ & $7(23.3 \%)^{B}$ & $38(42.2 \%)$ & \multirow{2}{*}{$0.003^{*}$} \\
\hline Absent & $10(33.3 \%)^{A}$ & $19(63.3 \%)^{B}$ & $23(76.7 \%)^{\mathrm{B}}$ & $52(57.8 \%)$ & \\
\hline \multicolumn{6}{|c|}{ Gum chewing } \\
\hline Present & $21(70.0 \%)^{A}$ & $12(40.0 \%)^{B}$ & $5(16.7 \%)^{c}$ & $38(42.2 \%)$ & \multirow{2}{*}{$<0.001^{*}$} \\
\hline Absent & $9(30.0 \%)^{A}$ & $18(60.0 \%)^{B}$ & $25(83.3 \%)^{C}$ & $52(57.8 \%)$ & \\
\hline \multicolumn{6}{|l|}{ Nail biting } \\
\hline Present & $20(66.7 \%)^{A}$ & $12(40.0 \%)^{B}$ & $4(13.3 \%)^{c}$ & $36(40.0 \%)$ & \multirow{2}{*}{$<0.001^{*}$} \\
\hline Absent & $10(33.3 \%)^{A}$ & $18(60.0 \%)^{\mathrm{B}}$ & $26(86.7 \%)^{C}$ & $54(60.0 \%)$ & \\
\hline \multicolumn{6}{|c|}{ Unilateral chewing } \\
\hline Present & 7 (23.3\%) & $6(20.0 \%)$ & 7 (23.3\%) & $20(22.2 \%)$ & \multirow{2}{*}{0.938} \\
\hline Absent & $23(76.7 \%)$ & $24(80.0 \%)$ & $23(76.7 \%)$ & $70(77.8 \%)$ & \\
\hline \multicolumn{6}{|c|}{ Foreign objects biting } \\
\hline Present & $3(10 \%)$ & $4(13.3 \%)$ & $2(6.7 \%)$ & 9 (10.0\%) & \multirow{2}{*}{0.905} \\
\hline Absent & $27(90 \%)$ & $26(86.7 \%)$ & $28(93.3 \%)$ & $81(90.0 \%)$ & \\
\hline \multicolumn{6}{|c|}{ Sleep bruxism } \\
\hline Present & 10 (33.3\%) & $8(26.7 \%)$ & 9 (30.0\%) & 27 (30.0\%) & \multirow{2}{*}{0.957} \\
\hline Absent & $20(66.7 \%)$ & $22(73.3 \%)$ & $21(70.0 \%)$ & $63(70.0 \%)$ & \\
\hline \multicolumn{6}{|c|}{ Awake bruxism } \\
\hline Present & $19(63.3 \%)^{A}$ & $11(36.7 \%)^{\mathrm{B}}$ & $4(13.3 \%)^{c}$ & $34(37.8 \%)$ & \multirow{2}{*}{$<0.001^{*}$} \\
\hline Absent & $11(36.7 \%)^{\mathrm{A}}$ & $19(63.3 \%)^{B}$ & $26(86.7 \%)^{C}$ & $56(62.2 \%)$ & \\
\hline \multicolumn{6}{|c|}{ Anterior open bite } \\
\hline Present & 1 (3.3\%) & $2(6.7 \%)$ & $0(0.0 \%)$ & $2(2.2 \%)$ & \multirow{2}{*}{0.770} \\
\hline Absent & 29 (96.7\%) & 28 (93.3\%) & 30 (100.0\%) & $88(97.8 \%)$ & \\
\hline \multicolumn{6}{|c|}{ Posterior cross-bite } \\
\hline Present & 5 (16.7\%) & 3 (10.0\%) & $2(6.7 \%)$ & 10 (11.1\%) & 507 \\
\hline Absent & 25 (83.3\%) & 27 (90.0\%) & $28(93.3 \%)$ & $80(88.9 \%)$ & 0.592 \\
\hline Overbite & & & & & \\
\hline Normal & 12 (40.0\%) & $17(56.7 \%)$ & 19 (63.3\%) & 48 (53.3\%) & 0212 \\
\hline$\geq 4 \mathrm{~mm}$ & $18(60.0 \%)$ & $13(43.3 \%)$ & $11(36.7 \%)$ & $42(46.7 \%)$ & \\
\hline Overjet & & & & & \\
\hline Normal & 23 (76.7\%) & 25 (83.3\%) & 27 (90.0\%) & 75(83.3\%) & 130 \\
\hline$\geq 5 \mathrm{~mm}$ & 7 (23.3\%) & 5 (16.7\%) & 3 (10.0\%) & 15 (16.7\%) & 0.434 \\
\hline Canine guid & & & & & \\
\hline Present & $13(43.3 \%)$ & $16(53.3 \%)$ & $18(60.0 \%)$ & 47 (52.2\%) & 0.468 \\
\hline Absent & 17 (56.7\%) & $14(46.7 \%)$ & $12(40.0 \%)$ & $43(47.8 \%)$ & 0.400 \\
\hline Mediotrusive & terferences & & & & \\
\hline Present & $12(40.0 \%)$ & 8 (26.7\%) & $8(26.7 \%)$ & $28(31.1 \%)$ & O 177 \\
\hline Absent & $18(60.0 \%)$ & 22 (73.3\%) & 22 (73.3\%) & 62 (68.9\%) & $0.4 / 2$ \\
\hline RCP-MI slide & & & & & \\
\hline Normal & 22 (73.3\%) & $21(70.0 \%)$ & $24(80.0 \%)$ & 67 (74.4\%) & 754 \\
\hline$\geq 2 \mathrm{~mm}$ & 8 (26.7\%) & 9 (30.0\%) & $6(20.0 \%)$ & $23(25.6 \%)$ & 0.134 \\
\hline$\geq 5$ missing & & & & & \\
\hline Present & $2(6.7 \%)$ & 1 (3.3\%) & $0(0.0 \%)$ & $3(3.3 \%)$ & ת7 77 \\
\hline Absent & 28 (93.3\%) & $29(96.7 \%)$ & 30 (100.0\%) & 87 (96.7\%) & 0.170 \\
\hline
\end{tabular}

*Statistically significant difference. Different capital letters indicate significant difference among groups. RCP-MI: retruded contact position to maximum intercuspation slide 
Table 2. Frequencies of "Yes" answers of awake bruxism (AB) among groups.

\begin{tabular}{lcc}
\hline Groups comparison & $\begin{array}{c}\text { Difference in means of "Yes" } \\
\text { answers for AB activity }\end{array}$ & p-value \\
\hline Group 1 x Group 2 & 15.03 & $0.049^{*}$ \\
Group 1 x Group 3 & 32.26 & $<0.001^{*}$ \\
Group 2 x Group 3 & 17.23 & $0.020^{*}$ \\
\hline
\end{tabular}

*Statistically significant difference. Group 1: painful TMJ clicking;

Group 2: painless TMJ clicking; Group 3: control group.

in changes in the composition and volume of the synovial fluid and promote to the production of inflammatory mediators. ${ }^{21}$

In the comparison among all groups, gum chewing and nail biting were OBs associated with painful TMJ clicking. These two OBs were also associated with painless TMJ clicking, but only when compared to the control group (Table 1). Gum chewing was one of the most prevalent $\mathrm{OB}(42.2 \%$ of the entire sample), and its association with painful TMJ clicking and with painless TMJ clicking was not surprising, since a higher incidence of TMJ clicking and arthralgia in individuals with the habit of chewing gum had already been reported, ${ }^{22,23,24}$ being a potential contributing factor for these conditions. ${ }^{22}$ Possibly, the high compressive forces within the joint due to the constant chewing contribute to squeeze the disc off the condyle and increase the sensitivity of retrodiscal tissues. ${ }^{25}$ Nail biting is one of the most persistent OB. A study showed that nail biting in childhood was a predictor of nail biting 20 years later. ${ }^{26}$ Nail biting was reported by $40 \%$ of the total sample, similar to a previous study (48\%). ${ }^{27}$ An experimental study suggested that the TMJ is loaded more heavily during incisor biting than during molar chewing. ${ }^{28}$ Also, incisal clenching has been reported to reduce anterior joint space and increase disc compression. ${ }^{29}$ These factors can explain the association between TMJ pain/clicking and nail biting found in this study.

Unilateral chewing was reported by $22.2 \%$ of the total sample without significant difference among groups or association with TMJ pain/clicking. These results differ from the study of Yalçin et al., ${ }^{30}$ that found a higher frequency (45.6\%) of unilateral chewing with a significant association with TMD. Differences in methodologies may explain the divergence of the results: in the study of Yalçin et al., ${ }^{30}$ presence, and not the frequency, of unilateral chewing was considered to establish the presence of the habit; in addition, no specific group of TMD was evaluated. Biting foreign objects was also not significantly associated with any group, and only $10 \%$ of the sample had this habit. Possibly, the overlapping of other OBs of a similar nature (such as gum chewing and nail biting) that presented higher prevalence, may explain the low frequency and the results of this variable.

SB is a masticatory muscle activity during sleep. ${ }^{17}$ In this study, $30 \%$ of the individuals presented a "Probable $\mathrm{SB}^{\prime \prime}$, with a similar prevalence among groups (Table 1 ). The similar prevalence, together with the fact that no instrumental assessment for SB was made, may have contributed to the absence of a significant association between SB and painful TMJ clicking. Nevertheless, this result is in accordance with previous studies that found no significant association between the presence of disc displacements ${ }^{31}$, arthralgia ${ }^{32}$, and self-reported $\mathrm{SB}$.

$A B$ is a masticatory muscle activity during wakefulness. ${ }^{17}$ Among adults, the prevalence of $\mathrm{AB}$ ranges between $22-30 \%{ }^{33}$ In this study, $37.8 \%$ of the individuals presented "Probable AB". In a study with a seven-day observation period, the frequency of real time report of $\mathrm{AB}$ activity in a sample of healthy young adults was $28.3 \%$ (being teeth contact and jaw clenching the most frequent activities). ${ }^{34}$ Considering EMA, $21.67 \%$ of the total sample provided positive real time responses of $\mathrm{AB}$ activity, but there was no differentiation among the various $\mathrm{AB}$ activities. It is interesting that some individuals with a negative self-report of $\mathrm{AB}$ had some positive answers to $\mathrm{AB}$ in the app. This fact underscores the importance of collecting real time data at multiple recording points during the day and within the environment of the individual for a more reliable evaluation of $A B$, as provided by EMA. Patients with painful TMJ clicking presented a higher frequency of $\mathrm{AB}$ activity $(37.43 \pm 33.75)$ than patients with painless TMJ clicking $(22.40 \pm 24.59)$ and the control group (5.17 \pm 6.05$)$. In the comparison among all groups, the presence of "Probable $\mathrm{AB}^{\text {" }}$ and the frequency of "Yes" answers for $\mathrm{AB}$ activity were significantly associated with painful TMJ clicking. These two variables were also associated with painless TMJ 
clicking only when compared to the control group (Table 1). These results agree with the literature, since $\mathrm{AB}$ has already been reported as a significant risk factor for disc displacement ${ }^{35}$, increasing also the risk for TMJ pain on jaw movement. ${ }^{36} \mathrm{~A}$ possible reason for the relationship between TMJ clicking, TMJ pain, and $\mathrm{AB}$ can be obtained from finite element model studies, showing that an abnormal distribution of stresses in the disc from prolonged clenching may facilitate disc displacement in symptomatic TMJ ${ }^{37}$ furthermore, relatively high stresses were observed in the retrodiscal tissues during clenching, ${ }^{38}$ reducing TMJ nutrient levels and producing an overload that could lead to severe damage to TMJ disc itself. ${ }^{39}$

In the present study, eight malocclusion features were addressed and none showed significant difference among groups, confirming that other factors (i.e., oral behaviors and bruxism) are more relevant for TMJ pain being a comorbid symptom in patients with TMJ clicking. Also, these results are in accordance with previous studies using multiple logistic regression analysis that suggest that there is no clinically relevant association between malocclusion and TMJ clicking or TMJ arthralgia. ${ }^{13,19}$

In this study, an association was found between OBs (of leaning with hand on the jaw, sleeping in a position that pressures the jaw, chewing gum, biting nail) and $\mathrm{AB}$ and painful TMJ clicking. Thus, clinically, maybe it is important to evaluate the presence of these factors on patients with painful TMJ clicking, so that their control can be included in the management of this condition. However, all results should be interpreted carefully. Limitations of the present investigation include the restricted population without gender pairing, the exclusion of other TMD conditions to isolate DDWR plus arthralgia, no TMJ image exam to exclude other intra-articular pathology that could be contributing to TMJ pain/clicking (degenerative joint disease), no polysomnographic records to evaluate $\mathrm{SB}$, and the study design (cross-sectional), which makes it impossible to establish a cause-effect relationship. Ideally, prospective studies should be conducted in the future. The present results corroborate the suggestion that the cause of arthralgia in some cases of TMJ clicking is not related to the anatomy of the TMJ itself, ${ }^{6,7,40}$ and clinical, somatosensorial, and psychosocial variables may be equally if not more important in painful TMJ clicking.

\section{Conclusions}

In view of the results and limitations of this study, it can be concluded that patients with painful TMJ clicking had a higher frequency and a statistically significant association with the behaviors of leaning with hand on the jaw, sleeping in a position that pressures the jaw, chewing gum, biting nail, and awake bruxism. Sleep bruxism and malocclusion were not related to painful TMJ clicking.

\section{Acknowledgment}

This study was financed in part by the Coordenação de Aperfeiçoamento de Pessoal de Nível Superior - Brasil (CAPES) - Finance Code 001. We also acknowledge the Coordenação de Aperfeiçoamento de Pessoal de Nível Superior - Brasil (CAPES) - Finance Code 001 for the PhD scholarship of Rodrigo Lorenzi Poluha (process, 88887.195891/2018-00) and the Sao Paulo Research Foundation (FAPESP) - Brazil for the Post-doctoral scholarship of Giancarlo De la Torre Canales (process 2017/21674-0).

\section{References}

1. Dworkin SF, LeResche L. Research diagnostic criteria for temporomandibular disorders: review, criteria, examinations and specifications, critique. J Craniomandib Disord. 1992;6(4):301-55.

2. Leeuw R, Klasser G, editors. Orofacial pain: guidelines for assessment, diagnosis, and management. 6th ed. Chicago: Quintessence; 2018.

3. Poluha RL, Canales GT, Costa YM, Grossmann E, Bonjardim LR, Conti PC. Temporomandibular joint disc displacement

with reduction: a review of mechanisms and clinical presentation. J Appl Oral Sci. 2019 Feb;27:e20180433.

https://doi.org/10.1590/1678-7757-2018-0433 
4. Marpaung CM, Kalaykova SI, Lobbezoo F, Naeije M. Validity of functional diagnostic examination for temporomandibular joint disc displacement with reduction. J Oral Rehabil. 2014 Apr;41(4):243-9. https://doi.org/10.1111/joor.12130

5. lodice G, Cimino R, Vollaro S, Lobbezoo F, Michelotti A. Prevalence of temporomandibular disorder pain, jaw noises and oral behaviours in an adult Italian population sample. J Oral Rehabil. 2019 Aug;46(8):691-8. https://doi.org/10.1111/joor.12803 PMID:30993737

6. Poluha RL, Canales GT, Bonjardim LR, Conti PC. Somatosensory and psychosocial profile of patients with painful temporomandibular joint clicking. J Oral Rehabil. 2020 Nov;47(11):1346-57. https://doi.org/10.1111/joor.13081

7. Poluha RL, Cunha CO, Bonjardim LR, Conti PC. Temporomandibular joint morphology does not influence the presence of arthralgia in patients with disk displacement with reduction: a magnetic resonance imaging-based study. Oral Surg Oral Med Oral Pathol Oral Radiol. 2020 Feb;129(2):149-57. https://doi.org/10.1016/i.0000.2019.04.016

8. Osiewicz MA, Lobbezoo F, Loster BW, Loster JE, Manfredini D. Frequency of temporomandibular disorders diagnoses based on RDC/TMD in a Polish patient population. Cranio. 2018 Sep;36(5):304-10. https://doi.org/10.1080/08869634.2017.1361052

9. Reissmann DR, John MT. [ls temporomandibular joint (TMJ) clicking a risk factor for pain in the affected TMJ]. Schmerz. 2007 Apr;21(2):131-8. German. https://doi.org10.1007/s00482-006-0518-z

10. Poluha RL, De la Torre Canales G, Bonjardim LR, Conti PC. Clinical variables associated with the presence of articular pain in patients with temporomandibular joint clicking. Clin Oral Investig. 2020 Nov. https://doi.org/10.1007/s00784-020-03685-8

11. Miyake R, Ohkubo R, Takehara J, Morita M. Oral parafunctions and association with symptoms of temporomandibular disorders in Japanese university students. J Oral Rehabil. 2004 Jun;31(6):518-23. https://doi.org/10.1111/j.1365-2842.2004.01269.x

12. Ohrbach R, Bair E, Fillingim RB, Gonzalez Y, Gordon SM, Lim PF, et al. Clinical orofacial characteristics associated with risk of first-onset TMD: the OPPERA prospective cohort study. J Pain. 2013 Dec;14(12 Suppl):T33-50. https://doi.org/10.1016/i.jpain.2013.07.018

13. Landi N, Manfredini D, Tognini F, Romagnoli M, Bosco M. Quantification of the relative risk of multiple occlusal variables for muscle disorders of the stomatognathic system. J Prosthet Dent. 2004 Aug;92(2):190-5. https://doi.org/10.1016/i.prosdent.2004.05.013

14. Cuschieri S. The STROBE guidelines. Saudi J Anaesth. 2019 Apr;13(5 Suppl 1):S31-4. https://doi.org/10.4103/sja.SJA_543_18

15. Armstrong RA. When to use the Bonferroni correction. Ophthalmic Physiol Opt. 2014 Sep;34(5):502-8. https://doi.org/10.1111/opo.12131

16. Barbosa C, Manso MC, Reis T, Soares T, Gavinha S, Ohrbach R. Cultural equivalence, reliability and utility of the Portuguese version of the Oral Behaviours Checklist. J Oral Rehabil. 2018 Dec;45(12):924-31. https://doi.org/10.1111/joor.12716

17. Lobbezoo F, Ahlberg J, Raphael KG, Wetselaar P, Glaros AG, Kato T, et al. International consensus on the assessment of bruxism: report of a work in progress. J Oral Rehabil. 2018 Nov;45(11):837-44. https://doi.org/10.1111/joor.12663

18. Stuginski-Barbosa J, Porporatti AL, Costa YM, Svensson P, Conti PC. Agreement of the International Classification of Sleep Disorders Criteria with polysomnography for sleep bruxism diagnosis: a preliminary study. J Prosthet Dent. 2017 Jan;117(1):61-6. https://doi.org/10.1016/i.prosdent.2016.01.035

19. Manfredini D, Peretta R, Guarda-Nardini L, Ferronato G. Predictive value of combined clinically diagnosed bruxism and occlusal features for TMJ pain. Cranio. 2010 Apr;28(2):105-13. https://doi.org/10.1179/crn.2010.015 PMID:20491232

20. Nitzan DW. Intraarticular pressure in the functioning human temporomandibular joint and its alteration by uniform elevation of the occlusal plane. J Oral Maxillofac Surg. 1994 Jul;52(7):671-9. https://doi.org/10.1016/0278-2391(94)90476-6 PMID:8006730

21. Tanaka E, Detamore MS, Mercuri LG. Degenerative disorders of the temporomandibular joint: etiology, diagnosis, and treatment. J Dent Res. 2008 Apr;87(4):296-307. https://doi.org/10.1177/154405910808700406

22. Winocur E, Gavish A, Finkelshtein T, Halachmi M, Gazit E. Oral habits among adolescent girls and their association with symptoms of temporomandibular disorders. J Oral Rehabil. 2001 Jul;28(7):624-9. https://doi.org/10.1046/i.1365-2842.2001.00708.x

23. Tabrizi R, Karagah T, Aliabadi E, Hoseini SA. Does gum chewing increase the prevalence of temporomandibular disorders in individuals with gum chewing habits? J Craniofac Surg. 2014 Sep;25(5):1818-21. https://doi.org/10.1097/SCS.0000000000000993

24. Correia D, Real Dias MC, Castanho Moacho A, Crispim P, Luis H, Oliveira M, et al. An association between temporomandibular disorder and gum chewing. Gen Dent. 2014 Nov-Dec;62(6):e33-6.

25. Osborn JW. The disc of the human temporomandibular joint: design, function and failure. J Oral Rehabil. 1985 Jul;12(4):279-93. https://doi.org/10.1111/j.1365-2842.1985.tb01283.x

26. Carlsson GE, Egermark I, Magnusson T. Predictors of bruxism, other oral parafunctions, and tooth wear over a 20-year follow-up period. J Orofac Pain. 2003;17(1):50-7. https://doi.org/10.1016/S0889-5406(03)00245-2

27. Mejersiö C, Ovesson D, Mossberg B. Oral parafunctions, piercing and signs and symptoms of temporomandibular disorders in high school students. Acta Odontol Scand. 2016;74(4):279-84. https://doi.org/10.3109/00016357.2015.1114668

28. Hylander WL, Bays R. An in vivo strain-gauge analysis of the squamosal-dentary joint reaction force during mastication and incisal biting in Macaca mulatta and Macaca fascicularis. Arch Oral Biol. 1979;24(9):689-97. https://doi.org/10.1016/0003-9969(79)90119-5

29. Takenami Y, Kuboki T, Acero CO Jr, Maekawa K, Yamashita A, Azuma Y. The effects of sustained incisal clenching on the temporomandibular joint space. Dentomaxillofac Radiol. 1999 Jul;28(4):214-8. https://doi.org/10.1038/sj.dmfr.4600443

30. Yalçın Yeler D, Yılmaz N, Koraltan M, Aydın E. A survey on the potential relationships between TMD, possible sleep bruxism, unilateral chewing, and occlusal factors in Turkish university students. Cranio. 2017 Sep;35(5):308-14. https://doi.org/10.1080/08869634.2016.1239851 
31. Blanco Aguilera A, Gonzalez Lopez L, Blanco Aguilera E, De la Hoz Aizpurua JL, Rodriguez Torronteras A, Segura Saint-Gerons $R$, et al. Relationship between self-reported sleep bruxism and pain in patients with temporomandibular disorders. J Oral Rehabil. 2014 Aug;41(8):564-72. https://doi.org/10.1111/joor.12172

32. Dias GM, Bonato LL, Guimarães JP, Silva JN, Ferreira LA, Grossmann E, et al. A study of the association between sleep bruxism, low quality of sleep, and degenerative changes of the temporomandibular joint. J Craniofac Surg. 2015 Nov;26(8):2347-50. https://doi.org/10.1097/SCS.0000000000002084

33. Melo G, Duarte J, Pauletto P, Porporatti AL, Stuginski-Barbosa J, Winocur E, et al. Bruxism: an umbrella review of systematic reviews. J Oral Rehabil. 2019 Jul;46(7):666-90. https://doi.org/10.1111/joor.12801

34. Bracci A, Djukic G, Favero L, Salmaso L, Guarda-Nardini L, Manfredini D. Frequency of awake bruxism behaviours in the natural environment. A 7-day, multiple-point observation of real-time report in healthy young adults. J Oral Rehabil. 2018 Jun;45(6):423-9. https://doi.org/10.1111/joor.12627

35. Michelotti A, Cioffi I, Festa P, Scala G, Farella M. Oral parafunctions as risk factors for diagnostic TMD subgroups. J Oral Rehabil. 2010 Mar;37(3):157-62. https://doi.org/10.1111/j.1365-2842.2009.02033.x

36. Huhtela OS, Näpänkangas R, Joensuu T, Raustia A, Kunttu K, Sipilä K. Self-reported bruxism and symptoms of temporomandibular disorders in finnish university students. J Oral Facial Pain Headache. 2016;30(4):311-7. https://doi.org/10.11607/ofph.1674

37. Hirose M, Tanaka E, Tanaka M, Fujita R, Kuroda Y, Yamano E, et al. Three-dimensional finite-element model of the human temporomandibular joint disc during prolonged clenching. Eur J Oral Sci. 2006 Oct;114(5):441-8. https://doi.org/10.1111/j.1600-0722.2006.00389.x

38. Abe S, Kawano F, Kohge K, Kawaoka T, Ueda K, Hattori-Hara E, et al. Stress analysis in human temporomandibular joint affected by anterior disc displacement during prolonged clenching. J Oral Rehabil. 2013 Apr;40(4):239-46. https://doi.org/10.1111/joor.12036

39. Wu Y, Cisewski SE, Coombs MC, Brown MH, Wei F, She X, et al. Effect of Sustained Joint Loading on TMJ Disc Nutrient Environment. J Dent Res. 2019 Jul;98(8):888-95. https://doi.org/10.1177/0022034519851044

40. Poluha RL, Grossmann E, Iwaki LC, Uchimura TT, Santana RG, Iwaki Filho L. Myofascial trigger points in patients with temporomandibular joint disc displacement with reduction: a cross-sectional study. J Appl Oral Sci. 2018 Jun;26(0):e20170578. https://doi.org/10.1590/1678-7757-2017-0578 